\title{
ТИПОЛОГИЯ МЕДИАРЕЧИ
}

УДК $659^{\circ} 4+81^{\prime} 42$

\section{Питч как текст бизнес-PR: коммуникативно-прагматический аспект}

\author{
Л.В. Балахонская \\ Санкт-Петербургский государственный университет, \\ Российская Федерация, 199034, Санкт-Петербург, Университетская наб., 7-9
}

Для цитирования: Балахонская, Л. В. (2021). Питч как текст бизнес-PR: коммуникативно-прагматический аспект. Медиалингвистика, 8 (3), 273-286. https://doi.org/10.21638/spbu22.2021.306

Рассматриваются питчинг как коммуникативная технология и питч как текст бизнесPR.Для более полного и корректного определения понятий «питч» и «питчинг» проанализирована семантика лежащей в их основе многозначной лексемы pitch. Описаны виды питчинга по сфере деятельности, целевому назначению и времени презентации. Предметом исследования стали текстовые особенности инвестиционного питча как инструмента PR-коммуникации. Основная цель работы - проанализировать структурно-содержательные компоненты инвестиционного питча в коммуникативно-прагматическом аспекте, включая характеристики адресанта, адресата, объекта, цели, функций и т. п. Материалом исследования послужили отобранные методом случайной выборки 28 видеозаписей питч-презентаций, представленных на зарубежных ТВ-шоу «Shark Tank» и «Dragon's Den» и размещенных также в социальной сети YouTube. Анализ материала показал, что текст питча строится на принципе сочетания стандарта и экспрессии, отмеченном в свое время В.Г.Костомаровым в отношении языка газеты. Тенденция к стандартизированности проявляется в типовой структуре питча, тенденция к экспрессивности - в использовании определенных вербальных и паравербальных средств, с помощью которых адресат стремится выразить субъективное отношение не только к содержанию речи, но и к адресату, воздействуя на его сознание и стимулируя к принятию нужных решений. Также проведен сравнительно-сопоставительный анализ питча как текста бизнес-PR и смежных явлений, таких как предложение о сотрудничестве, коммерческое предложение и предложение о спонсорстве, выявлены критерии разграничения указанных текстовых феноменов. На основе выявленных дифференциальных признаков предложено определение инвестиционного питча. Сделан вывод о том, что инвестиционный питч можно включить в ряд других предложений, исходящих от субъекта $\mathrm{PR},-$ предложения о сотрудничестве, коммер-

(c) Санкт-Петербургский государственный университет, 2021 
ческого предложения и предложения о спонсорстве, назвав его предложением об инвестициях или предложением для инвесторов.

Ключевые слова: питч, питчинг, питч-презентация, PR-текст, бизнес-PR.

\section{Постановка проблемы}

В последние два десятилетия питчинг стал довольно активно применяться в бизнес-коммуникации, в рамках которой сложилось понимание данного термина как краткой презентации нового проекта или идеи инвесторам с целью привлечения финансирования.

Происхождение термина питчинг связано с английским многозначным словом pitch, которое, по данным онлайн-словаря «ReWord», при употреблении в роли существительного может иметь значение «партия товара», а при употреблении в роли глагола - «выставлять на продажу» (в коммерции) или «бросать, кидать, подавать» (в спорте) [ReWord]. Принято считать, что в бизнес-коммуникацию термин пришел из спортивной сферы, прежде всего из тех видов спорта, где ведущую роль играет правильная подача (например, гольф, бейсбол, крикет). Питчинг как коммуникативная технология тоже должен основываться на правильной подаче (презентации) нового проекта или идеи заинтересованным группам общественности.

В основе успешного питчинга лежит умение выступающего расположить к себе аудиторию, вызвать у нее интерес, подать ключевую идею презентации в нетривиальной и доходчивой форме, обычно с помощью интригующей истории. Подобные умения соотносятся с еще одним значением слова pitch - «травить байки, рассказывать басни», отмеченным в словаре как разговорное [ReWord].

В наиболее полном виде семантика лексемы pitch проявляется в сложных словах и словосочетаниях. Так, значение сочетания high-pitchedvoice трактуется как «высокий голос», а значение слова pitchfork - как «вилы». Как замечено в статье К.А.Антуганова и Д.О.Виноградова, написанной под научным руководством автора настоящей статьи, «в семантической структуре данных терминов выделяется общий компонент - “зацепить”: высокий голос способен “зацепить” слушателей (переносное значение), вилы используются, чтобы “зацепить” сено (прямое значение)» [Антуганов, Виноградов 2020: 14-15].

Краткий семантический анализ многозначной лексемы pitch иллюстрирует суть питчинга как коммуникативной технологии, заключающейся в правильной подаче (презентации) нового проекта или идеи, способной «зацепить» внимание инвесторов.

Эффективность питчинга при продвижении бизнес-идей уже давно осознана зарубежными прдпринимателями, однако в российской практике питчи стали применяться значительно позже - чуть более десяти лет назад. Сравнительно небольшой опыт создания и презентации питчей в российской бизнес-среде и недостаточный уровень научного осмысления нового коммуникативного феномена в отечественной коммуникативистике делают актуальной проблему исследования текстовых особенностей питча с опорой на материалы зарубежных питч-презентаций. Поскольку питч не только способствует продвижению бизнес-начинания, но и оказывает влияние на формирование или развитие имиджа бизнес-субъекта, это дает возможность отнести питч к особой жанровой разновидности PR-текста. 


\section{История вопроса}

Впервые питчинг как коммуникативная технология был применен в конце прошлого века в западной киноиндустрии, прежде всего в Голливуде, где режиссер, продюсер или сценарист будущего фильма с помощью питч-презентации обращались к партнерам или инвесторам с просьбой поддержать новый проект (чаще всего финансово). Традиционно в киноиндустрии выделяются два вида питчинга: сценарный, с помощью которого сценаристы могут презентовать идею или готовый сценарий будущего фильма продюсерам, и продюсерский, целью которого является поиск партнеров для производства и софинансирования кинопроектов [Левина 2015: 24].

В России первый питчинг состоялся в 2007 г. в рамках кинофестиваля «Кинотавр». Это был продюсерский питчинг, который представлял целый ряд абсолютно новых продюсерских проектов. С тех пор питчинг на этом кинофестивале проводится регулярно. В нем участвуют проекты как известных продюсеров, так и новичков, жюри представлено именами маститых профессионалов, постоянно присутствуют представители международных кинофестивалей.

Питчинг успешно применяется не только в киноиндустрии, но и в других отраслях деятельности - книгопечатном деле, при производстве игр, выпуске различных продовольственных и промышленных товаров и т. п. Например, некоторые издательства (в частности, «Рипол-классик») организуют питчинг-сессии, на которых авторы могут презентовать свою рукопись экспертам - директорам и главным редакторам издательств, литературным критикам, журналистам специализированных изданий, известным писателям.

Исследователями отмечена эффективность питчинга при продвижении стартапов, под которыми понимается либо новый проект, либо компания, недавно появившаяся на рынке. Британский ученый Колин Кларк еще в 2008 г. писал о влиянии питчинга, под которым он понимал устную презентацию стартапера, на первоначальные инвестиционные решения бизнес-ангелов и приводил рекомендации по оптимальному взаимодействию питчера с потенциальными инвесторами стартапа. Автор установил непосредственную связь между коммуникативными навыками питчера (его способностью доступно презентовать новую бизнес-идею или продукт, умением четко отвечать на поставленные вопросы и т. п.) и поведением инвестора [Clark 2008].

Е.И. Королев, руководитель «Pitch School», в своей статье подробно описал основные смысловые компоненты правильно организованных питч-презентаций, на которые следует обратить внимание авторам стартап-проектов, для того чтобы потенциальные инвесторы определили их состоятельность и перспективность: описание продукта (проекта), сравнение с проектами конкурентов, команда по разработке, продвижению, управлению бизнесом, работе с партнерами и клиентами, анализ текущего состояния рынка, на котором работает стартап, и потенциал роста, бизнес-модель (включая финансовую), инвестиционную модель, перспективы развития [Королев 2019: 50].

В статье А.Легранд приведен кейс, в котором представлены основные этапы разработки питч-презентации стартап-проекта «Witget» (сервиса повышения конверсии сайта) для участия в отборе на «Startup Village» - крупнейшем стартап- 
событии в России, ежегодно проводимом фондом «Сколково». Жюри конкурса судит каждый проект с учетом трех критериев: инновационность, конкурентоспособность, монетизация. Автор делится опытом подготовки питч-презентации по предложенному организаторами плану, обращает внимание на важность визуализации выступления, дает советы по оптимизации слайдов [Легранд 2014].

Все исследователи сходятся во мнении, что питч-презентация проходит в условиях ограниченного времени. О.Клафф, автор книги «Идеальный питч. Революционный метод заключения крупных сделок», считает, что питч не должен занимать более 20 минут, так как далее человеческое внимание рассеивается [Клафф 2013]. Идеальное время для презентации проекта - от одной до нескольких минут. В зависимости от времени презентации выделяются три вида питчей:

1) elevator pitch - самая короткая презентация проекта, которую нужно успеть сделать за 30-60 секунд, т. е. за то время, пока питчер поднимается с инвестором на лифте. За столь ограниченное время можно выделить проблему, указать пути ее решения и обозначить необходимые финансовые вливания с перспективой доходности проекта. Главная цель elevator pitch - привлечь внимание потенциального инвестора и получить шанс на вторую встречу;

2) idea pitch занимает несколько минут и состоит из названия проекта, формулировки проблемы, указания путей решения, краткой характеристики рынка и основных конкурентов, описания бизнес-модели, включающей объем инвестиций, и представления команды - разработчиков проекта с указанием контактной информации;

3) funding pitch продолжается около 10 минут или чуть более и включает все блоки, выделенные в idea pitch, а также представляет более подробный анализ рынка и основных конкурентов, описание стратегии выхода на рынок, информацию о том, что уже сделано и каковы перспективы развития проекта [Молчан, Солонина, Болдырева 2017: 431-432].

С точки зрения поставленных целей исследователи выделяют следующие виды питчинга:

- медиапитчинг, применяемый в разных сферах деятельности при обязательном участии средств массовой информации; цель медиапитчинга - привлечь массовую аудиторию не напрямую, а опосредованно, через СМИ;

- питчинг мнений, целью которого является привлечение голосов и формирование общественного мнения, поиск союзников как в политической, так и в бизнес-сфере;

- инвестиционный питчинг, представляющий собой непосредственный акт коммуникации между питчером и потенциальным инвестором, цель которого заключается в получении финансирования проекта [Антуганов, Виноградов 2020: 15-16].

В соответствии с темой статьи для нас наибольший интерес представляет инвестиционный питчинг. 


\section{Описание методики исследования}

Объектом нашего исследования стал инвестиционный питчинг, предметом - текстовые особенности инвестиционного питча как инструмента PRкоммуникации.

Цель работы - проанализировать структурно-содержательные компоненты инвестиционного питча в коммуникативно-прагматическом аспекте, включая характеристики адресанта, адресата, объекта, цели, функций и т. п.

Одна из задач исследования - сравнительно-сопоставительный анализ инвестиционного питча как текста бизнес-PR и смежных явлений, таких как предложение о сотрудничестве, коммерческое предложение и предложение о спонсорстве, выявление интегральных и дифференциальных признаков указанных текстовых феноменов.

Материалом исследования послужили отобранные методом случайной выборки 28 видеозаписей питч-презентаций, представленных на зарубежных ТВшоу «Shark Tank» (https://abc.com/shows/shark-tank) и «Dragon's Den» (https://www. bbc.co.uk/programmes/b006vq92) и размещенных также в социальной сети YouTube (https://www.youtube.com/watch?v). Первое реалити-шоу такого рода было проведено в Японии в 2001 г., где оно называлось «Money Tigers». C 2005 г. шоу уже под названием «Dragon's Den» стало транслироваться в Великобритании на канале «ВВС Two», a c 2009 г. появилась американская версия реалити-шоу, названная «Shark Tank» и демонстрируемая на канале «ABC». В настоящее время существует множество версий данного реалити-шоу, которые транслируются примерно в тридцати странах мира.

Анализ материала осуществлялся в рамках описательного подхода с применением методов семантико-семиотического и лингвостилистического анализа языковых единиц.

\section{Анализ материала}

Цель инвестиционного питча - привлечь внимание потенциального инвестора и добиться финансирования нового проекта. Питч-выступление, как правило, ограничено несколькими минутами, в течение которых надо успеть рассказать о своей бизнес-идее так, чтобы заинтересовать аудиторию, поэтому текст питча должен строиться на принципе сочетания стандарта и экспрессии, о котором на примере языка газеты писал в свое время В.Г. Костомаров [Костомаров 1974: 23]. Стандарт обеспечивает более быстрое понимание сообщения, а экспрессия способствует воздействию текста на сознание адресата.

В условиях ограниченного объема текст питча должен иметь стандартную структуру, чтобы инвесторы, не затрачивая особых усилий, могли быстро вычленять в нем все значимые блоки. Организаторы конкурса новых проектов «Startup Village», проводимого фондом «Сколково», предложили следующую стандартную структуру питч-презентации:

- кто вы (название и логотип компании);

- какую проблему решает ваш проект;

- каков спрос на ее решение; 
- рынок/конкуренты;

- ваше решение: ключевая технология (кратко);

- ваше решение: преимущества перед конкурентами;

- бизнес-модель (как будете зарабатывать);

- маркетинг и продажи: как будете выходить на рынок;

- ключевые показатели: гипотезы, прогнозы, метрики успеха;

- команда: почему именно вы способны реализовать этот бизнес;

- текущий статус (что сделано), план-график (что и когда планируется);

- потребности в капиталовложениях (сколько нужно денег и на что) / предложение инвестору (что вы за них готовы предложить);

- контакты [Легранд 2014].

Анализ видеозаписей питч-выступлений западных предпринимателей показал, что такая структура скорее носит рекомендательный характер, близка к идеальной, но далеко не всегда соответствует реальности, так как новичок в бизнесе, предлагающий новую идею (чаще всего это индивидуальный предприниматель), обычно не способен самостоятельно сделать качественный анализ рынка и предложений конкурентов, разработать бизнес-модель, охарактеризовать ключевые показатели, представить гипотезы, прогнозы, метрики успеха. Этим объясняется использование упрощенной структуры устного выступления начинающих бизнесменов перед инвесторами в TB-шоу «Shark Tank» и «Dragon's Den». В структуре проанализированных питч-выступлений в указанных ТВ-шоу нами выделены следующие блоки.

1. Приветствие (формальное или менее формальное) и обращение к адресату: Hello dragons! Hi sharks! Менее формальное, повседневное приветствие Нi! в отношении незнакомых или малознакомых людей используется для демонстрации особого, доверительного отношения к ним, чтобы вызвать соответствующую реакцию. Форма обращения к адресату в данном случае зависит от названия ТВ-шоу, в рамках которого проводится питчинг: к инвесторам - членам жюри шоу «Shark Tank» обращаются словом sharks (aкyль), а к членам жюри шоу «Dragons' Den» словом dragons (драконы), используемыми в метафорических значениях.

2. Представление (указание адресанта): My name is Elisa and this is my husband and business partner Elias. Наряду с именем адресант часто указывает свой деловой статус и название компании, которой владеет или в которой работает: My name is Davison. I'm the founder and CEO of «Brightwheel».

3. Объект инвестирования (название и краткое описание товара или услуги): Together wefounded "Just Jerky" — anauthentic and all-natural beef jerky; I'm here today to introduce you to my innovative brand «Spice by Risa».

4. Цель питча (с указанием необходимой суммы инвестиций и ответным предложением для инвесторов): I'm looking for a seventy-five thousand pound investment in return for $12 \%$ share in my business. Иногда цель питча не ограничивается лишь материальной стороной - поиском инвестиций, а имеет более широкую перспективу: Firstly, we're here today seeking your mentorship. We're also here to ask for a $\$ 75000$ investment in return for $20 \%$ equity share in our company.

5. Занимательная история с указанием мотива/причины появления бизнесидеи или создания стартап-проекта: I am 10 years old but when I was 8 years old I really wanted a Lego set. But it costs \$400. The good news was my dad said I could have it. So I did what most of you probably would do. I started my own business. After 12 weeks I made 
nine hundred dollars after expenses, learned some valuable lessons and yes I got my Lego Star Wars. The experience is exactly why I created "Jack's Stands and Marketplaces"

6. Подробное описание объекта инвестирования (нового проекта/продукта, выводимого на рынок) с указанием потребностей клиентов, которые он удовлетворяет, целевой аудитории, новизны идеи проекта, технических характеристик, функций и т. п. Описание объекта сопровождается аргументами, доказывающими инновационность проекта, функциональность и другие свойства: That's why I invented "The Kooler». It's the world's only cooler within a cooler. First it's a double wall insulated cooler that holds a gallon of ice water that you can drink while exercising or throughout the day. If you want a protein shake or an energy drink while you're training here you go! If you want a snack or a meal replacement drink after, the cooler comes with the second shaker bottle. I designed it to hold some protein or carbohydrate powder for your post exercise nutrition. Now, remember, the ice water goes in here and when the shakers go in the water keeps them cold. "The Kooler» keeps three drinks all together inside one ice-cold container. В приведенном тексте при описании проекта приводятся аргументы, демонстрирующие его уникальность и отличия от аналогичных продуктов на рынке.

7. Положение нового продукта на рынке в настоящее время и перспективы развития: "Just Jerky» is currently stocked in over 400 stores across Australia and we're on track to be available in a thousand outlets by the end of financial year. Over the next four years it is to turn into 5000 stores whilst also covering a unique position in the global beef jerky market.

8. Заключительное обращение к инвесторам, оформленное обычно в виде вопроса, содержащего стимулирующее предложение: So, sharks? Our challenge and question to you is who wants to make money? В заключительном обращении к инвесторам питчер может привести дополнительные аргументы в защиту своего проекта, стимулирующие положительное решение потенциального инвестора, и выразить уверенность в дальнейшем сотрудничестве: Sharks, this is unique opportunity to build a massive business that has a massive impact on people's everyday lives. And that's something that we hear every day. So I hope you're joining Serena and our team and bringing «Brightwheel» to every preschool, every daycare and every family across the globe.

Разумеется, представленная типовая структура питча, выявленная в результате структурно-содержательного анализа текстов устных выступлений предпринимателей перед потенциальными инвесторами в рамках зарубежных TB-шоу «Shark Tank» и «Dragon's Den», может быть адаптирована к реальным коммуникативным условиям: ситуации, месту, времени, цели, объекту, типу адресанта и адресата и т. п. Например, в некоторых питчах после приветствия и представления сразу называется сумма необходимых вложений и предлагаемая доля акций нового проекта и уже после этого указывается название проекта и описывается его суть. Не во всех питчах присутствует анализ рыночной ситуации и даются прогнозы. В коротких питчах, как правило, отсутствует занимательная история. Однако указанные различия несущественны, что дает основания считать выделенную нами текстовую структуру питча типовой, стандартной.

Для того чтобы текст питча достиг своей цели, он должен быть воздействующим, нести в себе экспрессию. С помощью экспрессивных средств языка говорящий или пишущий может выразить субъективное отношение к содержанию или адресату речи. Экспрессивность выражается прежде всего лексическими единицами, в семантической структуре которых, помимо предметно-логического значения, 
имеется оценочный компонент: Beef jerky is a super trendy and loved snack food, however Australians have not yet had the opportunity to experience a compelling and authentic brand that is a real standout in quality taste and enjoyment. В данном примере использован целый ряд оценочных слов, с помощью которых говорящий не только выражает свое отношение к описываемому новому продукту - восхищение, гордость, желание познакомить с ним как можно больше людей, но и хочет сформировать положительное отношение к нему у инвесторов, одновременно формируя позитивный имидж разработавшей данный инновационный продукт компании.

Экспрессивность часто выражается с помощью переносных значений слов, выступающих в роли метафор. Среди метафор высокой степенью экспрессии обладают зооморфные, используемые для характеристики человека путем скрытого сравнения с животным и передачи определенного отношения к нему. В зависимости от названия шоу предприниматели во время питч-презентаций метафорически обращаются к потенциальным инвесторам - членам жюри конкурса инновационных проектов как к акулам, драконам, тиграм, львам и т. п.: Hello, dragons!, Hello, tigers!, Hi, sharks!

Например, называя инвесторов словом sharks (в переносном значении), питчер подчеркивает их опыт и высокий статус в бизнесе, умение взаимодействовать с конкурентами, применять жесткие меры, поглощать мелкие компании, «выплывать» в случае кризисных ситуаций и т.п. (Ср. устойчивое сочетание в русском языке «акула бизнеса», которое обозначает опытного, успешного предпринимателя, обладающего превосходными деловыми качествами и имеющего неоспоримые преимущества перед конкурентами.) Разумеется, метафора shark в обращении к инвесторам воспринимается ими как комплимент их деловым качествам и настраивает на ответную позитивную реакцию.

Безусловно, питч-презентация с элементами экспрессивности речи не только демонстрирует психологическое состояние питчера, но и имеет целью воздействовать на сознание потенциальных инвесторов.

О.Клафф при написании питча предложил использовать разработанные им шесть рекомендаций, по начальным буквам которых составил аббревиатуру STRONG, назвав ею свой «революционный» метод заключения крупных сделок посредством питча. Воздействующий эффект названия метода (аббревиатуры) основан на омонимии с лексемой strong - «сильный, мощный, весомый». По замыслу автора, метод STRONG должен восприниматься как «сильный» в противовес «слабым» традиционным методам взаимодействия субъектов бизнес-коммуникации.

Setting the Frame. Вначале следует установить фрейм, который представляет собой определенную структуру, рамку и отождествляется со стандартной стереотипной ситуацией, состоящей из множества конкретных однородных условий.

Telling the Story. Внимание слушателей можно привлечь интригующей историей, чтобы разрушить фрейм аналитика и повернуть решение в свою пользу.

Revealing the Intrigue. Необходимо постепенно раскрыть интригу, продолжая удерживать внимание и интерес аудитории.

Offering the Prize. Слушателям можно предложить награду, и тогда они станут воспринимать как награду вас.

Nailing the Hookpoint - прием «ловля на крючок». В конце питча слушатели уже должны быть эмоционально вовлечены в озвученную питчером идею, поэтому вполне уместно спросить об их отношении к проекту. 
Getting a Decision. Следует стимулировать принятие решения инвесторами [Клафф 2013].

Приведенные рекомендации позволяют воздействовать на сознание потенциального инвестора с помощью посланий, основанных на определенных фреймах, интриге и новизне. Интрига и новизна хорошо вписываются в занимательные истории, которыми сопровождается описание новой идеи в питче. Именно они чаще всего привлекают внимание аудитории, заставляют сопереживать герою рассказа. Любая занимательная история включает средства речевого воздействия и манипулирования (см., например: [Balakhonskaya et al. 2020; Сергеева 2012]), благодаря которым адресант речи в питче предстает в наиболее выгодном свете, демонстрируя свой социальный статус и превосходство над конкурентами, описываемый продукт характеризуется как инновационный и обладающий самыми замечательными свойствами, а адресат наделяется почти «отцовскими» качествами: справедливостью, опытом, дальновидностью в принятии решений. Манипулятивный прием «эксплуатация интереса к сопутствующей информации», выделенный Е. В.Сергеевой в отношении рекламного дискурса [Сергеева 2018], эффективен и в PR-коммуникации, в частности в тексте питча. Занимательная история, по сути, и является той «сопутствующей информацией», которая придает интригу питчу.

Резюмируя вышеизложенное, согласимся с мнением О.Клаффа о том, что успех питча обеспечивают три составляющие: статус, внимание, фрейм-контроль [Клафф, 2013]. Представляя перевод книги О.Клаффа на русский язык, А.И.Барановский подчеркивает важность проблемы статуса для стартаперов, которые во время питча должны показывать свой доминирующий статус, используя соответствующие вербальные и паравербальные средства коммуникации. Не менее важно умение привлечь внимание аудитории, что обеспечивается захватывающей, интригующей историей, в которой раскрывается мотив создания нового проекта. В процессе питч-презентации необходимо также осуществлять контроль на уровне всех четырех фреймов, среди которых выделяются интрига, вознаграждение, фрейм времени, моральное превосходство [Барановский 2014: 170].

\section{Результаты исследования}

Проведенное исследование позволяет утверждать, что питч можно отнести к PR-текстам на основании того, что он обладает рядом дифференциальных признаков, присущих им: функционирует в публичном пространстве (в сфере экономических отношений и бизнеса), содержит PR-информацию о деятельности базисного субъекта и инициирован им, нацелен на конструирование оптимальной коммуникационной среды данного субъекта, формирование или поддержание его имиджа. Питч, как и некоторые другие новые жанры и поджанры электронной коммерческой коммуникации (см., например: [Гончарова 2019]), порожденные интернет-средой, характеризуется прямым авторством и адресован узким целевым группам, в данном случае потенциальным инвесторам. Как правило, питч распространяется при личном контакте со стейкхолдерами и сопровождается мультимедийной презентацией.

Основные функции питча - воздействующая (выражает отношение к содержанию и адресату речи), имиджеформирующая (влияет на имидж и репутацию 
субъекта), информационная (передает актуальную информацию о новом объекте), коммуникативная (способствует налаживанию обратной связи с адресатом), гносеологическая (расширяет знания о мире), аксиологическая (ценностно ориентирующая). Доминирующей функцией питча следует признать воздействующую, которая, как пишет М.Р.Желтухина, реализуется в трех разновидностях: аттрактивной, связанной с привлечением и удержанием внимания, персуазивной, предполагающей убеждение адресата, и суггестивной, в основе которой лежит внушение [Желтухина 2003]. Действительно, питч сначала должен привлечь внимание аудитории какими-то новыми или интересными фактами, с помощью тщательно подобранных аргументов убедить слушателей в оригинальности и конкурентоспособности представляемой идеи или продукта, внушить мысль о выгодности предложения и необходимости инвестировать в него средства.

По мнению М. В.Бусыгиной, питч имеет некоторое сходство с пресс-релизом и рекламой на основании того, что все указанные разновидности коммуникаций являются способом «информирования о нововведениях и изменениях в работе или продуктах», но, в отличие от рекламы и пресс-релиза, «питч-письмо имеет персонифицированный характер и предлагает идею для написания истории, достойной внимания прессы» [Бусыгина 2016: 121].

Мы считаем питч одним из современных инструментов бизнес-PR, так как с его помощью бизнес-субъект (коммерческая организация или индивидуальный предприниматель) может осуществить успешную коммуникацию с заинтересованными стейкхолдерами, в первую очередь с потенциальными инвесторами. Правильно спланированный и представленный питч должен в лаконичной, «цепляющей» форме передать достаточно полную, объективную информацию о новом проекте, подкрепленную необходимыми вербальными и визуальными аргументами, демонстрирующими выгоду для инвесторов. Концепт «выгода» сближает питч с предложением о сотрудничестве, коммерческим предложением и предложением о спонсорстве [Балахонская 2019: 137-138]. Различия между ними базируются на дифференциальных признаках, касающихся характеристик адресанта, адресата, объекта, цели коммуникации и функциях.

Изучение немногочисленной специальной литературы по проблемам питчинга (прежде всего инвестиционного) и анализ реальных примеров проведения питчпрезентаций в рамках зарубежных TB-шоу «Shark Tank» и «Dragon’s Den» позволили обнаружить следующие дифференциальные характеристики питча как предложения для инвестора:

- адресант - индивидуальный предприниматель, коммерческая или общественная организация, желающие привлечь инвестиционные средства для реализации своего проекта;

- адресат - потенциальные инвесторы, готовые профинансировать проект на условиях коммерческой выгоды (как правило, за определенный процент от дохода);

- объект - новый продукт (проект), нуждающийся в инвестировании для производства и выхода на рынок;

- цель - формирование оптимальной коммуникационной среды бизнессубъекта для привлечения финансирования какого-либо начинания (проекта); 
- функции - воздействующая, имиджеформирующая, информационная, познавательная, коммуникативная, аксиологическая и некоторые другие.

Таким образом, питч можно включить в ряд других корпоративных предложений, исходящих от субъекта $\mathrm{PR}$, - предложения о сотрудничестве, коммерческого предложения и предложения о спонсорстве, назвав его предложением об инвестициях или предложением для инвесторов.

Выявленные характеристики позволяют сформулировать определение инвестиционного питча следующим образом: питч - это жанр PR-текста, функционирующий в пространстве бизнес-коммуникаций, инициируемый базисным субъектом - индивидуальным предпринимателем или коммерческой организацией, адресованный потенциальным инвесторам, созданный с целью формирования оптимальной коммуникационной среды бизнес-субъекта и привлечения финансовых вложений в какой-либо инновационный проект или идею, выполняющий прежде всего воздействующую и имиджеформирующую функции.

\section{Выводы}

Таким образом, питч является одной из жанровых разновидностей $\mathrm{PR}$-текста, функционирующей в системе публичных коммуникаций в бизнес-среде. Выявление дифференциальных признаков питча как PR-текста связано с установлением типа адресанта, адресата, объекта, цели и функций.

Как и в большинстве медийных текстов, в основе питча лежит принцип сочетания стандарта и экспрессии. Тенденция к стандартизации проявляется в типовой структуре питча. Нами выделены следующие структурные компоненты инвестиционного питча: приветствие и обращение к адресату; представление адресанта с указанием делового статуса и названия компании, которой владеет или в которой работает субъект; краткое описание объекта инвестирования; цель питча с указанием необходимой суммы инвестиций и ответным предложением для инвесторов; занимательная история, в которой раскрывается мотив (причина) появления бизнес-идеи или создания стартап-проекта; подробное описание объекта инвестирования с указанием потребностей клиентов, которые он удовлетворяет, целевой аудитории, новизны идеи проекта, технических характеристик, функций и т. п.; положение нового продукта на рынке и перспективы развития; заключительное обращение к инвесторам, призванное стимулировать положительное решение.

Наряду с тенденцией к стандартизированности, в тексте питча наблюдается тенденция к экспрессивности, благодаря которой в полной мере проявляется его воздействующая функция. С помощью экспрессивных речевых средств адресант может выразить свое субъективное отношение не только к содержанию речи, но и к адресату, воздействуя на его сознание и стимулируя принятие нужных решений.

Эффективность питча как текста бизнес-PR в значительной степени базируется на его имиджеобразующей функции, способности формировать оптимальную коммуникационную среду социального субъекта. Цель питча как PR-текста - оптимизация коммуникативного взаимодействия между базисным субъектом и значимым сегментом общественности - инвестиционным сообществом. Чем увереннее будет вести себя питчер во время презентации инновационного проекта и быстрее сможет расположить к себе аудиторию, чем больше аргументов сможет 
привести в его пользу, доказать уникальность идеи и отсутствие рисков при финансовых вложениях, тем выше вероятность положительного решения потенциальных инвесторов, которые оценивают не только выгодность предложения, но и имидж и репутацию бизнес-субъекта.

\section{Литература}

Антуганов, К. А., Виноградов, Д. О. (2020). Питчинг как коммуникативная технология. В Современная медиасреда: традиции, актуальные практики и тендениии. Взгляд молодых исследователей (с. 13-19). Санкт-Петербург: С.-Петербург. гос. ун-т; Институт «Высш. шк. журн. и масс. коммуникаций».

Балахонская, Л.В. (2019). Предложение о сотрудничестве как текст бизнес-коммуникации. В Медиа в современном мире. 58-е Петербургские чтения (с. 137-138). Санкт-Петербург: С.-Петербург. гос. ун-т; Институт «Высш. шк. журн. и масс. коммуникаций».

Барановский, А.И. (2014). «Идеальный питч» Орена Клаффа: статус, внимание, фрейм-контроль. Личные продажи, 2 (26), 166-171.

Бусыгина, M.В. (2016). Питч-письмо как инструмент PR-коммуникации. Известия Волгоградского гос. пед. ун-та. Филологические науки, 1 (105), 121-124.

Гончарова, А. А. (2019). Обзор поджанров коммерческой электронной медиакоммуникации. Медиатингвистика, 6 (4), 512-525. https://doi.org/10.21638/spbu22.2019.407.

Желтухина, М.Р. (2003). Тропологическая суггестивность масс-медиального дискурса: о специфике речевого воздействия тропов в языке СМИ. Волгоград: ВФ МУПК.

Значение слова Pitch. B ReWord: онлайн-словарь. Электронный pecypc http://reword.org/online/?dic_ eng_rus=yes\&recent $10=$ yes\&s_query=pitch.

Клафф, О. (2013). Идеальный питч. Революиионный метод заключения крупных сделок. Москва: Манн, Иванов и Фербер.

Королев, Е.И. (2019). Кому отдать миллион. Руководство по инвестированию в стартапы. Банковское дело, 5, 50-53.

Костомаров, В. Г. (1974). Русский язык на газетной полосе. В Психолингвистические проблемы массовой коммуникации. Москва: Наука.

Легранд, А. (2014). Команда Witget: как подготовить идеальный питч. Электронный pecypc https:// vc.ru/tribuna/3850-startup-village.

Лёвина, С.А. (2015). Продвижение стартап-проектов с помощью технологий питчинга. Научные труды Северо-Западного института управления, 6, 5 (22), 23-28.

Молчан, А.С., Солонина, С.В., Болдырева, Л.В. (2017). Особенности реализации инновационных бизнес-идей в Российской Федерации. Экономика и предпринимательство, 1, 428-432.

Сергеева, Е.В. (2012). К вопросу о некоторых манипулятивных приемах в текстах предвыборной агитации (на материале кампании 2011 г.). Политическая лингвистика, 2, 46-52.

Сергеева, Е. В. (2018). Особенности манипулятивного приема «эксплуатация интереса к сопутствующей информации» в рекламном дискурсе (на материале раздела «Порядок вещей» в журнале Story). Медиалингвистика, 5 (4), 484-493. https://doi.org/10.21638/spbu22.2018.408.

Balakhonskaya, L. V., Gavra, D. P., Beresneva, I. V., Sadirova, K. K. (2020). Markers of Manipulation in the Electoral Communication in a Digital Environment. In Proceedings of the 2020 IEEE Communication Strategies in Digital Society Seminar, ComSDS 2020. Электронный pecypc https://www.scopus.com/ authid/detail.uri?authorId=57195608280.

Clark, C. (2008). The impact of entrepreneurs' oral "pitch" presentation skills on business angels' initial screening investment decisions. Venture Capital: An International Journal of Entrepreneurial Finance, $10(3), 257-279$.

Статья поступила в редакцию 14 февраля 2021 г.; рекомендована в печать 18 апреля 2021 г.

Контактная информация:

Балахонская Людмила Владимировна - канд. филол. наук, доц.; l.balakhonskaya@spbu.ru 


\title{
Pitch as a business PR-text: Communicative and pragmatic aspect
}

\author{
L. V. Balakhonskaya \\ St. Petersburg State University, \\ 7-9, Universitetskaya nab., St. Petersburg, 199034, Russian Federation
}

For citation: Balakhonskaya, L. V. (2021). Pitch as a business PR-text: Communicative and pragmatic aspect. Media Linguistics, 8 (3), 273-286. https://doi.org/10.21638/spbu22.2021.306 (In Russian)

The article discusses pitching as a communication technology and a pitch as a business PRtext. For a more complete and correct definition of the concepts of a pitch and pitching, the semantics of the multi-valued pitch lexeme underlying them are analyzed. The types of pitching are described by the field of activity, by the intended purpose and by the time of the presentation. The subject of the study was the textual features of the investment pitch as a PR communication tool. The main purpose of the work is to analyze the structural and content components of the investment pitch in the communicative and pragmatic aspect, including the characteristics of the addresser, addressee, object, goal, functions, etc. The material for the study was selected using the method of random sampling of 28 video recordings of pitch presentations presented on the foreign TV shows Shark Tank and Dragons' Den, posted on the social network YouTube. The analysis of the material showed that the text of the pitch is based on the principle of combining standard and expression, noted by V.G. Kostomarov, in relation to the language of the newspaper. The tendency towards standardization is manifested in the typical structure of the pitch, the tendency towards expressiveness - in the use of certain verbal and paraverbal means, with the help of which the addresser seeks to express a subjective attitude not only to the content of speech, but also to the addressee, influencing his consciousness and stimulating him to make the necessary decisions. Based on the identified differential features, the definition of an investment pitch is proposed. It is concluded that the investment pitch can be included in a number of other proposals coming from the PR subject - proposals for cooperation, commercial proposals and proposals for sponsorship, calling it an offer for investors.

Keywords: pitch, pitching, pitch presentation, PR-text, business PR.

\section{References}

Antuganov, K.A., Vinogradov, D.O. (2020). Pitching as a communicative technology. In Sovremennaia mediasreda: traditsii, aktual'nye praktiki i tendentsii. Vzgliad molodykh issledovatelei (pp. 13-19). St. Petersburg: "Higher School of Journalism and Mass Communications" St. Petersburg State University. (In Russian)

Balakhonskaia, L. V. (2019). Collaboration proposal as a text of business communication. In Media v sovremennom mire. 58-e Peterburgskie chteniia (pp. 137-138). St. Petersburg: "Higher School of Journalism and Mass Communications" St. Petersburg State University. (In Russian)

Balakhonskaia, L. V., Gavra, D. P., Beresneva, I. V., Sadirova, K. K. (2020). Markers of Manipulation in the Electoral Communication in a Digital Environment. In Proceedings of the 2020 IEEE Communication Strategies in Digital Society Seminar, ComSDS 2020. Retrieved from https://www.scopus.com/authid/ detail.uri?authorId $=57195608280$.

Baranovskii, A.I. (2014). "Perfect pitch" by Oren Cluff: status, attention, frame control. Lichnye prodazhi, 2 (26), 166-171. (In Russian)

Busygina, M. V. (2016). Pitch-message as an instrument of PR communication. Izvestiia Volgogradskogo gos. ped. un-ta. Filologicheskie nauki, 1 (105), 121-124. (In Russian)

Clark, C. (2008). The impact of entrepreneurs' oral "pitch" presentation skills on business angels' initial screening investment decisions. Venture Capital: An International Journal of Entrepreneurial Finance, 10 (3), 257-279.

Goncharova, A. A. (2019). Commercial e-communication subgenres review. Media Linguistics, 6 (4), $512-$ 525. https://doi.org/10.21638/spbu22.2019.407. (In Russian) 
Klaff, O. (2013). Perfect pitch. A revolutionary method for making large transactions. Moscow: Mann, Ivanov i Ferber Publ. (In Russian)

Korolev, E. I. (2019). Who to give a million to. Guide to investing in startups. Bankovskoe delo, 5, 50-53. (In Russian)

Kostomarov, V. G. (1974). Russian on the newspaper page. In Psikholingvisticheskie problemy massovoi kommunikatsii. Moscow: Nauka Publ. (In Russian)

Legrand, A. (2014). Widget command: how to prepare the perfect pitch. Retrieved from https://vc.ru/ tribuna/3850-startup-village. (In Russian)

Levina, S. A. (2015). Promotion of startup projects using pitching technologies. Nauchnye trudy SeveroZapadnogo instituta upravleniia, 6, 5 (22), 23-28. (In Russian)

Molchan, A.S., Solonina, S. V., Boldyreva, L. V. (2017). Features of implementation of innovative business ideas in the Russian Federation. Ekonomika i predprinimatel'stvo, 1, 428-432. (In Russian)

Sergeeva, E. V. (2012). To the question of some manipulative techniques in the texts of election campaigning (based on the material of the 2011 campaign). Politicheskaia lingvistika, 2, 46-52. (In Russian)

Sergeeva, E. V. (2018). Specificity of manipulative method of use the interest to additional information in the advertising discourse (in the section "Order of things" of the "Story" magazine). Media Linguistics, 5 (4), 484-493. https://doi.org/10.21638/spbu22.2018.408. (In Russian)

The meaning of the word Pitch. In ReWord: onlain-slovar'. Retrieved from http://reword.org/online/?dic _ eng_rus=yes\&recent $10=$ yes\&s_query=pitch. (In Russian)

Zheltukhina, M.R. (2003). Tropological suggestiveness of the mass of medial discourse: on the specifics of the speech influence of tropes in the language of mass media. Volgograd: VF MUPK Publ. (In Russian)

Received: February 14, 2021

Accepted: April 18, 2021

Author's information:

Liudmila V.Balakhonskaya - PhD in Philology, Associate Professor; l.balakhonskaya@spbu.ru 